http://jmscr.igmpublication.org/home/

ISSN (e)-2347-176x ISSN (p) 2455-0450

crossref DOI: https://dx.doi.org/10.18535/jmscr/v7i8.43

Journal Of Medical Science And Clinical Research

\title{
An Observational study to evaluate the factors aggravating or precipitating acne in Indian adolescent vs adult patients
}

Authors

Dr Amit Chauhan ${ }^{1}$, Dr Geeta Ram Tegta ${ }^{2}$, Dr Ghanshyam Verma ${ }^{3}$

${ }^{1}$ Ex Resident, Department of Dermatology, Indira Gandhi Medical College, Shimla

${ }^{2}$ Professor and Head of Department, Department of Dermatology, Indira Gandhi Medical College, Shimla

${ }^{3}$ Associate Professor, Department of Dermatology, Indira Gandhi Medical College, Shimla

\begin{abstract}
Background: Acne vulgaris is one of the most common skin disorders worldwide. The incidence of adult acne is also increasing now a days and the factors precipitating/aggravating acne in adolescents vs adult patients are not entirely the same. We tried to find out the prevalence of adult vs adolescent acne and the factors affecting the aggravation or precipitation of acne in two groups.

Material and Methods: A total of 80 patients, diagnosed with acne attending the outdoor patient department over a period of one year were included in the study. They were examined thoroughly and data obtained was recorded on designed proformas.

Results: Forty two patients (52.5\%) in this study were in the age group between 15 to 25 years and thirty eight patients were above 25 years, out of which most common age group was 26 to 35 years. Oil based cosmetics and hormonal changes were common factors in both groups, while stress was more common in adolescents and facials and cosmetic procedures were common in adult group.

Conclusion: Now a day's adult acne are also becoming common and despite some of the factors are common in both, but some other factors are quite different in case of adolescent vs adult acne and a knowledge of these can help patients to reduce the chance of flare-ups.
\end{abstract}

\section{Introduction}

Acne vulgaris is one of the most common skin disorders worldwide, and typically presents as non inflammatory lesions, inflammatory lesions, or a mixture of both, due to blockage and/or inflammation of pilosebaceous units (hair follicles and their accompanying sebaceous gland). Acne is typically vacillating in its course and occurs primarily at puberty with a prevalence of almost $95 \%,{ }^{1}$ but now a day's prevalence of adult patients with acne (acne beyond the age of 25 years) ${ }^{2}$ is also increasing. There are periodic flares, some of which may be accounted for by various triggers and aggravating factors. It is therapeutically rewarding to identify the concerned triggers and aggravating factors and be able to deal with them. Various factors have been implicated in the aggravation or precipitation of acne including use of vegetable oils, coconut oil, almond oil, olive oil, and rye oil as moisturizers and revitalizers (as body rubs), facial massage, the repeated exposure to oil vapors during cooking, cosmetics including some sunscreens, friction and pressure, sweating, stress, sunlight, menstruation, pregnancy, certain drugs, high glycemic index diet or dairy products consumption. ${ }^{3}$ Thus, through our study we tried to 
evaluate various factors contributing to the flare ups of acne, and their relation with respect to age of the patient. We tried to find out that which factors are responsible in case of adoloscents and which are culprit in adult acne (whether persistent or late onset)

\section{Material and Methods}

The study comprised of 80 patients with a clinical diagnosis of acne vulgaris who attended the outpatient clinic of dermatology over a period of 1 year. Written informed consent was taken from all the patients. Ethical clearance was not obtained as it was an observational study. It was an observational study conducted in a case study mode using convenience sampling.

A detailed history regarding age of onset, duration, type of acne, family history, whether there was any exacerbation related to food, cosmetics, drugs, emotional stress, seasonal variation, sunlight, application of cosmetics or menstruation was taken.

The primary outcome measures include finding out most common age group. Patients were divided into two groups adolescent group (Group G1 of age 13-25 years) and adult group (Group G2 of age >25 years). Secondary outcome measures include the factors affecting the aggravation or precipitation of acne in two groups. Relevant data was entered in MS-Excel worksheet and analysed using SPSS version 17.

\section{Results}

Forty two patients $(52.5 \%)$ in this study were in the age group between 15 to 25 years (Group G1) and thirty eight patients were above 25 years (Group G2), out of which most common age group was 26 to 35 years. [Table 1] Out of the 80 patients included in the study, $51(63.7 \%)$ were female and $29(36.3 \%)$ were male. There was a clear female predominance with a female-to-male ratio as $1.76: 1$.

Fifty five patients $(68.8 \%)$ had a duration of $<5$ years whereas $10(12.5 \%)$ patients had a total duration of $>15$ years. Thirty five $(43.7 \%)$ patients had first-degree relatives with a present or past history of acne.

Among precipitating/aggravating factors, in adolescent group, Group G1, twelve (44.4\%) patients could attribute their exacerbation of the lesions to the premenstrual phase, followed by use of oil based cosmetics in fifteen $(35.7 \%)$ patients, while stress was another major reason in adolescent group that is in eleven (26.2\%) patients. In adult group, Group G2, major factors involved were use of oil based cosmetics in eighteen $(47.4 \%)$ patients, followed by facial cosmetic procedures in sixteen $(42.1 \%)$ patients, premenstrual phase in ten $(41.7 \%)$ patients, drug induced in twelve $(31.6 \%)$ patients. [Table 2]

Table 1: Age wise and Sex wise distribution of patients

\begin{tabular}{|c|c|c|c|c|c|}
\hline \multicolumn{2}{|l|}{ Age } & \multicolumn{2}{|c|}{ Number(\%) } & $\begin{array}{c}\text { Male } \\
\text { Number(\%) }\end{array}$ & $\begin{array}{c}\text { Female } \\
\text { Number(\%) }\end{array}$ \\
\hline \multicolumn{2}{|c|}{$\begin{array}{l}\text { Group G1 } \\
\text { (13-25 years) }\end{array}$} & \multicolumn{2}{|c|}{$42(52.5)$} & $15(18.8)$ & $27(33.8)$ \\
\hline \multirow{4}{*}{$\begin{array}{l}\text { Goup } \\
\text { G2 } \\
\text { (>25 } \\
\text { years) }\end{array}$} & $26-35$ & \multirow{4}{*}{$\begin{array}{r}38 \\
(47 . \\
5)\end{array}$} & $\begin{array}{c}24 \\
(30)\end{array}$ & $9(11.3)$ & $15(18.8)$ \\
\hline & $36-45$ & & $\begin{array}{c}10 \\
(12.5)\end{array}$ & $4(5)$ & $6(7.5)$ \\
\hline & $46-55$ & & $3(3.8)$ & 0 & $3(3.6)$ \\
\hline & $>55$ & & $1(1.3)$ & $1(1.3)$ & 0 \\
\hline
\end{tabular}

Table 2: Precipitating or aggravating factors among two groups

\begin{tabular}{|l|c|c|}
\hline & $\begin{array}{c}\text { Group G1 } \\
\text { (Total number }= \\
42)\end{array}$ & $\begin{array}{c}\text { Group G2 } \\
\text { (Total number }= \\
38)\end{array}$ \\
\hline Oil based cosmetics & $15(35.7)$ & $18(47.4)$ \\
\hline $\begin{array}{l}\text { Facial massage/Facial } \\
\text { cosmetic procedures }\end{array}$ & $6(14.3)$ & $16(42.1)$ \\
\hline Seasonal & $5(11.9)$ & $8(21.0)$ \\
\hline Sweating & $10(23.8)$ & $8(21.0)$ \\
\hline Repeated friction & $3(7.1)$ & $1(2.6)$ \\
\hline $\begin{array}{l}\text { Menstruation (calculated } \\
\text { out of female patients) }\end{array}$ & $12(44.4)$ & $10(41.7)$ \\
\hline Stress & $11(26.2)$ & $6(15.8)$ \\
\hline Dietary & $8(19.0)$ & $7(18.4)$ \\
\hline Drug induced & $4(9.5)$ & $12(31.6)$ \\
\hline Sunlight & $3(7.1)$ & $2(5.3)$ \\
\hline Smoking & $3(7.1)$ & $5(13.2)$ \\
\hline Total* & 86 & 98 \\
\hline
\end{tabular}

*Total number is more than defined number because of the presence of more than one precipitating/aggravating factor among patients. 


\section{Discussion}

The main finding in our study is that though, acne are most common among adolescent population yet adult onset acne is also on arise. Even in our case we found, $52.5 \%$ patients were below 25 years, but again about $47.5 \%$ patients were above 25 years, though in adult group also maximum patients were among 26 to 35 years. Although acne usually declines after the age of 40 years, in our study, it was still present in $10 \%$ of patients beyond 45 years.

Acne is more common in women. ${ }^{2,4}$ Similarly, in our study women were predominantly affected $(63.7 \%)$ as compared to men $(36.3 \%)$. This may represent an increased awareness in women seeking treatment as compared to men. However, a community-based survey of more than 700 adults older than 25 years also reported clinical facial acne in $12 \%$ of women and $3 \%$ of men. ${ }^{2}$ Hormonal factors such as premenstrual flare ups, increased use of cosmetics and exposure to hot and humid conditions while cooking may play a role in increased prevalence of acne in women.

Among the precipitating/aggravating factors, use of oil based cosmetics has significant contribution both in adolescent and adult acne. In India, use of vegetable oils, coconut oil, almond oil, olive oil, and rye oil is popular. Such oils are traditionally used as moisturizers and revitalizers (as body rubs), and for hair dressing. Oils form an occlusive film over the applied area and cause comedogenesis and aggravation of acne in the acne-prone areas. ${ }^{5}$

Facials are also popular and are regularly undertaken by women for a feeling of freshness, rejuvenation, suppleness of skin, tightening of skin, and for delaying the onset of wrinkles. ${ }^{6}$ Facials were observed to have caused acneiform eruptions in $33.1 \%$ of subjects in a study in India. ${ }^{6}$ Even in our study, they contributed as a precipitating factor in $42.1 \%$ of adult acne while the number was quite less in case of adolescent acne, owing to the fact that with age females become more, conscious regarding skin ageing and thus go for cosmetic procedures.Many cosmetics are comedogenic (acne cosmetica/acne venenata). Some of the comedogenic cosmetic ingredients are: isopropyl myristate, cocoa butter, lanolin, stearyl alcohol, and oleic acid. Apart from this, sweating in a hot humid environment causes deterioration in $15 \%$ of acne patients. ${ }^{7}$ In our study almost equal percentage of adolescent and adult (23.8\% and $21 \%$ ) were affected by sweating.

Repeated pressure from helmets, backpacks, and tight collars can induce comedones and papules. Follicular irritation from regular shaving, waxing, and laser hair removal and is sometimes associated with papules and pustules. But this factor had quite less incidence in our study.

Premenstrual flare of acne reportedly occurs in $70 \%$ of female acne patients. ${ }^{8}$ Typically, the patient experiences a fresh breakout of inflammatory lesions, often 1-2 in number, on or near the chin, in the week preceding the commencement of the menstrual flow. There is hydration-induced cyclical narrowing of the pilosebaceous orifice between days 16-20 of the menstrual cycles, ${ }^{8}$ resulting in acne flare ups. Progesterone and estrogen have pro- and antiinflammatory effects, and alteration or modulation of these hormones may be another explanation. ${ }^{8,9}$ In our study it was also a major factor responsible for acne flare up in both groups.

Stress is another factor implicated in aggravation of acne (vide supra) while acne itself induces stress. In our study, it was mainly responsible in adolescent group owing to immaturity in handling stress in young patients.

Recently, diet has also been linked to acne. Dietary intake of dairy products in high school students were correlated with physician diagnosed severe acne in women, a positive association was established in a US based study. ${ }^{10}$ It was hypothesized that milk and dairy products carry hormones and bioactive molecules that have the potential to aggravate acne. Data also suggests that high glycemic load foods (sugared foods) were responsible for rising prevalence of acne in developed societies. ${ }^{11}$ Hyperglycemic food intake results in increase in insulin like growth factor 
1(IGF1) and a decrease in insulin like growth factor binding protein 3 (IGFBP3) leading to hyperandrogenism, seborrhea, and follicular hyperkeratosis. ${ }^{11}$ However, the exact role of diet in the pathogenesis of acne remains unclear and controversial, and many dermatologists continue to propagate the conviction that acne is independent of diet.

Though, in our study we didn't find much relation between diet and acne, probably because the patients are also not able to relate it to acne.

This is well known. The causative drugs are halogenated compounds, progestogens, oral contraceptive pill (sometimes it helps acne), corticosteroids, isoniazid, and lithium. ${ }^{3}$ In our study most of the drug induced acneiform eruptions were because of the use of topical corticosteroids out of ignorance.

Sunlight is generally beneficial to acne although psoralens and UVA (PUVA) therapy may sometimes induce or aggravate acne, ${ }^{12}$ This has been observed in India and is locally referred to as 'Goa acne'. Though not a significant contributer in our case. Though there is no clear association between smoking and acne. One study showed a linear relationship between acne prevalence and the number of cigarettes smoked daily. ${ }^{3} \mathrm{~A}$ more recent cross-sectional study has concluded that the anti-inflammatory effects of smoking may inhibit the development of papulopustular acne, more so in girls than boys. ${ }^{13}$

Overall, we were able to conclude that though certain factors like use of oil based cosmetics, hormonal influences were common in both age groups, but certain factors were entirely different in two groups. Stress was a common factor among adolescents, while facials and cosmetic procedures were more common in adult patients.

\section{Conclusion}

We thereby conclude that now a day's adult acne are also becoming common and despite some of the factors are common in both, but some other factors are quite different in case of adolescent vs adult acne and a knowledge of these can help patients to reduce the chance of flare-ups.

\section{Bibliography}

1. Burton JL, Cunliffe WJ, Stafford I, Shuster S. The prevalence of acne vulgaris in adolescence. Br J Dermatol 1971;85:11926.

2. Goulden V, Clark S, Cunliffe W. Postadolescent acne: A review of clinical features. Br J Dermatol 1997;136:66-70.

3. Kubba R, Bajaj A K, Thappa D M, Sharma R, Vedamurthy M, Dhar S, Criton S, Fernandez R, Kanwar A J, Khopkar U, Kohli M, Kuriyipe V P, Lahiri K, Madnani N, Parikh D, Pujara S, Rajababu K K, Sacchidanand S, Sharma V K, Thomas J. Factors precipitating or aggravating acne. Indian J Dermatol Venereol Leprol 2009;75, Suppl S1:10-2.

4. Williams C, Layton AM. Persistent acne in women. Implications for the patient and for therapy. Am J ClinDermatol 2006;7: 281-90.

5. Singh R, Reddy B, Singh G. Acne cornea or oil-acne simulating Pityriasisrubrapilaris. Indian J Dermatol Venereol Leprol 1976;42:79.

6. Khanna N, Datta Gupta S. Rejuvenating facial massage: A bane or boon? Int J Dermatol 2002;41:407-10

7. Simpson NB, Cunliffe WJ. Disorders of the sebaceous glands. In: Burns $\mathrm{T}$, Breathnach S, Cox N, Griffiths C, editors. Rook's textbook of dermatology, $7^{\text {th }}$ ed. Oxford: Blackwell Science; 2004. p. 43.31-32

8. Cunliffe WJ, Gollnick HPM. Acne: Diagnosis and management. London: Martin Dunitz; 2001. p. 49-67.

9. Williams M, Cunliffe WJ. Explanation of premenstrual acne. Lancet 1973;2:1055-7.

10. Adebamowo CA, Spiegelman D, Danby EW, Frazier AL, Willett WC, Holmes MD. High school dietary dairy intake and 
teenage acne. J Am AcadDermatol 2005;52:207-14.

11. Cordain L, Lindeberg S, Hurtado M, Hill $\mathrm{K}$, Eaton Bbrand-Miller J. Acne vulgaris: A disease of western civilization. Arch Dermatol 2002;138:1584-90.

12. Mills OH, Kligman AM. Ultraviolet phototherapy and photochemotherapy of acne vulgaris. Arch Dermatol 1978;114: 221-3.

13. Rombouts S, Nijsten T, Lambert J. Cigarette smoking and acne in adolescents: Results from a cross-sectional study. J Eur Acad Dermatol Venereol 2007;21:326-33. 